\title{
Effects of $\mathrm{LaPO}_{4}$ coating on the performance of $\mathrm{LiNi}_{0.5} \mathrm{Co}_{0.2} \mathrm{Mn}_{0.3} \mathrm{O}_{2}$ cathode material for lithium ion batteries
}

\author{
Xiaodong Jiang ${ }^{1}$, Zhentao Yuan ${ }^{1}$, Jianxiong Liu ${ }^{1}$, Xin Jin ${ }^{2}$, Liying Jin ${ }^{3}$,Peng Dong ${ }^{1}$, Yingjie Zhang ${ }^{1}$, \\ Yuhan Yao ${ }^{1}$, Qi Cheng ${ }^{1}$, Cheng Liu ${ }^{1}$, Yannan Zhang ${ }^{1, *}$, Xiaohua Yu, ${ }^{1,4, *}$ \\ ${ }^{1}$ National and Local Joint Engineering Laboratory for Lithium-ion Batteries and Materials Preparation \\ Technology, Key Laboratory of Advanced Battery Materials of Yunnan Province, Kunming University \\ of Science and Technology, Kunming 650093, China. \\ ${ }^{2}$ Shanxi Enginerring Vocational College, Taiyuan 030009, China. \\ ${ }^{3}$ Shandong Institute of Physical Education and Sports, Jinan 250102, China. \\ ${ }^{4}$ National Engineering Research Center of Waste Resource Recovery, Kunming University of Science \\ and Technology, Kunming 650093, China. \\ *E-mail: zyn_legolass@163.com, xiaohua_y@163.com
}

doi: $10.20964 / 2018.03 .13$

Received: 6 November 2017 / Accepted: 4 January 2018 / Published: 5 February 2018

$\mathrm{LiNi}_{0.5} \mathrm{Co}_{0.2} \mathrm{Mn}_{0.3} \mathrm{O}_{2}$ (NCM-523) cathode material is coated with 2.0, 4.0 and $6.0 \mathrm{wt} \%$ of $\mathrm{LaPO}_{4}$ via liquid phase coating method. The structure, morphology and electrochemical properties of surface modified $\mathrm{LiNi}_{0.5} \mathrm{Co}_{0.2} \mathrm{Mn}_{0.3} \mathrm{O}_{2}$ materials are characterized by $\mathrm{X}$-ray diffraction (XRD), scanning electron microscopy (SEM), electrochemical workstation, inductively coupled plasma emission spectrometry (ICP), and constant current charge and discharge test. The consequence indicates that the structure of the materials is not transformed significantly before and after coating. The cycling performance and rate capability of the coated samples are improved significantly. The capacity retention of $4 \mathrm{wt} \%$-coated NCM-523 sample at $1 \mathrm{C}$ and $5 \mathrm{C}$ are $95.17 \%$ and $93.71 \%$ between 2.8 and $4.2 \mathrm{~V}$ after 100 cycles, respectively. The Correspond to capacity retention of pristine sample at $1 \mathrm{C}$ and $5 \mathrm{C}$ are only $77.25 \%$ and $73.16 \%$. It can be ascribed to that $\mathrm{LaPO}_{4}$ coating layer can effectively avoid the side reaction between active materials and electrolytes. Furthermore, the $\mathrm{LaPO}_{4}$ coating layer can effectively reduce the dissolution of transition metal elements in electrolyte and the deposition of high impedance metal fluorides on the electrode surface.

Keywords: $\mathrm{LiNi}_{0.5} \mathrm{Co}_{0.2} \mathrm{Mn}_{0.2} \mathrm{O}_{2}$; cathode; coating; co-precipitation method 
(C) 2018 The Authors. Published by ESG (www.electrochemsci.org). This article is an open access article distributed under the terms and conditions of the Creative Commons Attribution license (http://creativecommons.org/licenses/by/4.0/). 